\title{
Revolution in the Street. Women, Workers, and Urban Protest in Veracruz, 1870-1927
}

El año de 2002 despertó una polémica en el entorno sociopolítico del estado de Veracruz: a los cien años de la terminación de la construcción del puerto profundo en Veracruz, y para celebrar ese hecho fundamental en el crecimiento de las actividades èconómicas de la entidad y de la república, las autoridades municipales del puerto plantearon erigir en esa ciudad una estatua del ex presidente $y$ ex dictador Porfirio Díaz. No obstante el casi total desinterés entre las generaciones jóveñes en México por la historia de la Revolución, en esta ocasión, entre las clases dirigentes actuales se mostró una gran vigencia de una serie de elementos constitutivos de la sociedad contemporánea: en particular la fuerza de las imágenes creadas durante la Revolución y durante la etapa de consolidación de ésta como Estado e ideología de gobierno. Estas imágenes y puntos discursivos nos mostraron dos cosas: por un lado, no se han muerto los fantasmas de la dictadura y de la reacción a ella: la Revolución de 1910; por el otro, la resolución del conflicto

\footnotetext{
* Andrew Grant Wood, Revolution in the Street. Women, Workers, and Urban Protest in Veracruz, 1870-1927, Wilmington, Scholarly Resources, 2001.
}

reciente en el puerto sobre la colocación o no de la estatua, indicó que todavía no tenemos la madurez para discutir los axiomas constitutivos del Estado revolucionario.

Esa coyuntura porteña proporcionó un telón de fondo apropiado para la consideración del libro que aquí se reseña, por varias razones. En primer lugar, tenemos que el punto de arranque del texto se refiere al momento en que el Estado mexicano opta por acelerar su entrada en el mundo moderno impulsando, entre otras cosas, una serie de inversiones fuertes en su infraestructura. Para el puerto de Veracruz estos impulsos redundaron en la construcción de dos vías ferroviarias que lo unían con el Altiplano, y también en la terminación de las obras portuarias que han causado la reciente trifulca política entre el gobierno estatal y las autoridades del municipio de Veracruz. En segundo lugar, el tema central del estudio - los movimientos urbano-populares en la ciudad y puerto de Veracruz- se sitúa en un lugar importante dentro de la hagiografía de la historia regional y la Revolución en Veracruz.

$\mathrm{Si}$ en los salones de distintos niveles de educación pública, y en varias 
de las acciones de Estado de la década de 1990, la Revolución deja de pesar como algo significativo, los años que suelen ser llamados radicales en el estado de Veracruz (1915-1932, años más, años menos) no dejan de despertar el interés de investigadores. La entrega de Andrew Grant Wood representa una adición a una larga lista bibliográfica que trata este periodo, y en particular los fenómenos sociales que se gestaron en el espacio del puerto y ciudad de Veracruz. Aun cuando el título del libro sugiere una temática extremadamente amplia, se trata a fin de cuentas de una reconstrucción pormenorizada del movimiento inquilinario que ocupó la atención de la clase política, la burguesía y el principal periódico locales a lo largo de casi toda la década de 1920. En opinión de Wood, ya es tiempo de abandonar aquella idea según la cual las movilizaciones multitudinarias de los inquilinos de Veracruz y, en menor grado las de otras ciudades en el estado, son una reacción espontánea de los trabajadores por sus pésimas condiciones de vida, y de empezar a construir una nueva visión de este proceso histórico - la modernización- como un coadyuvante en la creación de las condiciones que serían el detonante de la "Revolución en las calles" ("Revolution in the Street"), como el autor llama al movimiento encabezado por Herón Proal.
A la vez, el autor pretende situar su estudio en el contexto de lo que él llama el "despertar de la sociedad civil" en México a partir de la década de 1980, aduciendo que el estudio de las luchas populares en Veracruz plantea una serie de preguntas importantes sobre la relación entre el Estado y la sociedad civil (p. xvi).

Wood pretende explicar las protestas de los inquilinos de Veracruz a través de tres factores: la emergencia de un discurso popular, dirigido a cuestiones de justicia social y a las condiciones de vida; las redes sociales que se formaban en torno al movimiento obrero y que se entrecruzaban con las culturas de la vecindad - y a través de las cuales se relacionaban las acciones de hombres y mujeres-, y el desarrollo de nuevas oportunidades políticas para las demandas populares, que se daban a la luz de la debilidad del gobierno federal (p. xvii).

La exposición del tema comienza con una presentación de los proyectos de modernización en el estado y las consecuencias que éstos tuvieron en el crecimiento desordenado e insalubre de la ciudad de Veracruz. La rápida construcción de vecindades y patios, fuera del control de las autoridades de la ciudad impuso una serie de condiciones adversas para la vida de los trabajadores y sus familias; no obstante, Wood asevera que de esas adversidades surgieron las bases y las redes de sociabilidad que posibilitaron la articu- 
lación de las protestas de la década de 1920 (p. 9). Desafortunadamente, esta relación entre malas condiciones de vida en las casas, patios y vecindades, y una capacidad para la movilización queda sólo como un enunciado que flota por encima de lo que resta del texto, sin que se haga una demostración clara de cómo emerge, se consolida y se reproduce entre las distintas capas de la sociedad en rebelión durante los años veinte. $Y$ no son pocas las aseveraciones que aparecen a lo largo del libro sin sustento y sin un desarrollo adecuado. ${ }^{1}$

El primer capítulo "The Process and Politics of Modernity in Veracruz", es la única parte del texto que justifica el periodo anunciado en el título del libro: 1870-1927. Y realmente, esas páginas sirven como una especie de preámbulo al tema central del libro. Los otros ocho capítulos se dedican al periodo revolucionario y la construcción del régimen posrevolucionario, y a los sucesos en el puerto

1 Otro caso se encuentra en la página 12, donde se dice que la invasión norteamericana de 1914 "hizo más, sin embargo, que marcar aun otra defensa heroica de la nación; memorias colectivas forjadas durante ese evento despertaron una conciencia política en los porteños mientras que luchaban por encontrar su lugar en el nuevo orden revolucionario" [traducción mla]. En la página 17 , se repite que la invasión fue una chispa para el desarrollo de la conciencia popular en el puerto, misma que se traduciría en acciones sobre la cuestión del alojamiento en la ciudad. Interesante que sea la idea, no se demuestra. de Veracruz vinculados con el movimiento inquilinario. Aun cuando el título de la obra hace una referencia vaga a mujeres, trabajadores y protesta urbana, el libro trata básicamente el movimiento inquilinario: la mención a las mujeres parece obedecer más a la necesidad académica ${ }^{2}$ actual de incluir algún dejo de género; a lo largo del texto, las páginas que se dedican a esta cuestión son escasas y nos aportan muy poco más de lo que se sabía a través de la extensa literatura sobre ese movimiento y/o sobre aquellos años en el puerto de Veracruz. Tampoco la calidad de trabajadores que se apunta en el subtítulo recibe mucha atención en el libro.

El relato de los acontecimientos en el estado, incluyendo las fisuras en los grupos de elite tanto en la región como a nivel federal, y el desenvolvimiento del movimiento inquilinario, está bien logrado. Las tres líneas explicativas anunciadas por el autor al principio del libro se recuperan a lo largo del texto, pero el que más atención recibe de esos tres factores es la cuestión de las elites políticas y la formación del Estado posrevolucionario, no obstante que el texto

2 i Correctness!: concepto relevante en el contexto del reconocimiento de los derechos de minorfas. Es decir, rendir tributo a lo que se considera correcto, aun cuando no hay un desarrollo de acuerdo a los enunciados en el ámbito correcto. 
tiene extensas secciones narrativas de la lucha callejera de los inquilinos.

Tal vez este libro resulte de utilidad considerable para un público angloparlante en cuanto que logra una narración coherente de los sucesos urbanos de la década de 1920 en la ciudad de Veracruz. Sin embargo, en el ámbito mexicano, este libro aporta poco por encima de lo que existe en la literatura, tanto de la escrita por participantes y/o observadores directos de los acontecimientos (José Mancisidor, Rafael Ortega con todo y su poco ingenioso seudónimo de Leafar Agetro, Rafael García Auli, por ejemplo), o por autores más recientes (Mario Gill, Heather Fowler, Olivia Domínguez Pérez, Paco Ignacio Taibo II y, especialmente, Octavio García Mundo). En aras de la construcción de la nueva historia urbana, este libro representa una aportación mínima. Un supuesto importante del libro sería el desarrollo de lạs formas de sociabilidad en las vecindades y patios que constituyeron los semilleros para la formación del Sindicato Revolucionario de Inquilinos, es decir, el primer factor que utiliza el autor como explicación del fenómeno bajo la lupa. ${ }^{3}$ Sin embargo, este factor queda

${ }^{3}$ A propósito, un aspecto que habría sido muy útil para el lector sería la consideración de la geografia del descontento urbano, con un mapeo de la localización de los principales sitios mencionados en el texto. opacado por la presencia de la figura de Herón Proal y de su necia y aguerrida compañera de batalla, María Luisa Marín. Y si la intención del libro es esclarecer el fenómeno urbano y las movilizaciones que engendra, es menester alcanzar la estructuración de ese fenómeno tanto desde la perspectiva de adentro como de afuera mas el libro concentra sus mayores esfuerzos en la contextualización de la gran política, de las luchas entre las facciones revolucionarias y sus gobiernos. $\mathrm{Y}$ es precisamente en ese sentido que se cuenta ya con una literatura abundante y profunda.

Hace pocos años, un investigador lanzó una llamada a la reflexión sobre el significado de la radical década de 1920 en Veracruz. Un elemento que se resaltó en la publicación que resultó de esa convocatoria, ${ }^{4}$ fue el problema de cómo entrecruzar estudios que tratan las organizaciones de clase (sean de campesinos o de obreros), con movimientos que denominamos populares y/o urbanos, para así alcanzar una comprensión de los procesos complejos de aquellos años. En ese momento, parecía que la veta más prometedora consistía en el estudio de los fenómenos más ligados al dominio popular que a las organi-

${ }^{4}$ Manuel Reyna Muñoz (coord.), Actores sociales en un proceso de transformación: Veracruz en los años veinte, Universidad Veracruzana, Xalapa, 1997. 
zaciones de clase y su lucha política. No obstante esa veta interesante, no se llegó a un fin concluyente, de la misma manera que el libro de Wood no se acerca a una visión de conjunto de la sociedad porteña en esos años, sino que se concentra en los actos de los inquilinos y su tormentosa relación con los distintos niveles de autoridad: es decir, se ven la manifestación y la protesta, sin que conozcamos la estructuración real de las mismas. Todavía nos queda la tarea de redondear nuestro interés por la década de 1920 en Veracruz con conclusiones que van más allá de los hechos heroicos, la avanzada social de las organizaciones sindicales y campesinas, o de los gobernantes visionarios; y más que nada, queda por comprender qué pasó con esas características tan destacadas ( $a$ ahora mitificadas?) del estado en aquellos años en el transcurso de los tiempos. Se despertaba la sociedad civil (entendida como el enorme residual, después de descontar a las "elites de poder”, según el autor): ¿será cierto, o en su caso, cuándo y cómo volvió a dormir?, ya que hoy día se pregona la posible y lenta construcción de la sociedad civil como un actor consciente y participativo. Si bien este libro representa una buena narración, la reconstrucción de un fenómeno, no alcanza su pretensión amplia de darnos elementos de comprensión para la sociedad de hoy. En su lugar, nos relata una situación ya señalada por James C. Scott en sus obras, ${ }^{5}$ a saber, cómo las fuerzas populares vigilan a las elites para escoger su momento para actuar. A fin de cuentas, ese enfoque resulta ser una especie de réplica de lo que nos enseñó hace unos cuarenta años el Che Guevara, quien dijo que la revolución no se hace simplemente cuando existen las condiciones objetivas (el hambre y la pobreza) sino también las subjetivas (las fisuras en las estructuras de ejercicio del poder, guerras, crisis económicas, invasiones, etcétera.).

\section{David Skerritt Gardner Instituto de Investigaciones Histórico-Sociales, Universidad Veracruzana}

5 En particular, "Everyday Forms of Peasant Resistence", Journal of Peasant Studies, enero de 1986, vol. 13, núm. 2, pp. 5-35, y Domination and the Arts of Resistance: Hidden Transcripts, Yale University Press, New Haven, 1990. 